Joan C. Bevan MD DRCOG FFARCS,

Celeste Johnston RN DEd, Margaret J. Haig MD FRCPC, Guy Tousignant MD FRCPC, Simon Lucy MD FRCPC, Vanessa Kirnon BA, Irene K. Assimes MD, Ruben Carranza MD

\section{Preoperative parental anxiety predicts behav- ioural and emotional responses to induction of anaesthesia in children}

Parental presence at induction of anaesthesia is desirable if it makes the child happier and more cooperative. This study evaluated the emotional and behavioural responses of children to being accompanied by a parent at induction of anaesthesia in a paediatric day-care surgical centre. One hundred and thirty-four patients (aged 2-10 yr, ASA physical status I or II) were divided into two groups by day of surgery, to have a parent present at induction of anaesthesia (treatment group), or to be unaccompanied (control group). Before, and at one week after surgery, the child's fears and behaviour were scored by the Hospital Fears Inventory (HFI) and Behavioural Questionnaire $(B Q)$, and parental anxiety by the Parents' Questionnaire $(P Q)$ before and at one week after surgery. The Global Mood Scale (GMS) was used to assess the child's behaviour and the Visual Analogue Scale (VAS) to assess the parent's anxiety on arrival for surgery and at induction of anaesthesia. All patients and parents were disturbed by the experience, but to the same degree in the treatment and control groups. Subgroups of "calm" and "anxious" parents were identified by a median split of their preoperative VAS scores. Children in the "calm-treatment," "calm-control" and "anxious-control" subgroups were similarly upset at induction. Children in the "anxious-treatment" subgroup were the most disturbed at induction, and significantly

\section{Key words}

ANAESTHESIA: paediatric;

INDUCTION: anaesthesia;

PSYCHOLOGICAL RESPONSES.

From the Departments of Anaesthesia and Nursing Rescarch, Montreal Children's Hospital and McGill University, Montreal, Quebec.

This project was funded in part by a grant from the Montreal Children's Hospital Research Institute for salary support towards V.K. (Department of Nursing).

Address correspondence to: Dr. J.C. Bevan, Department of Anaesthesia, Montreal Children's Hospital, 2300 Tupper St., Montreal, Quebec H3H 1P3 more than those in the "anxious-control" subgroup. Preoperative parental anxiety levels also correlated with the child's fears and behaviour one week after surgery. Therefore, parental anxiety should be assessed preoperatively to allow "calm" parents to be present at induction if they wish, and "anxious" parents to be excluded and receive counselling and support.

La présence des parents au moment de l'induction de l'anesthésie est désirable si elle rend l'enfant plus heureux et plus coopératif. Cette étude a évalué les réponses émotionnelles et le comportement des enfants accompagnés de leurs parents lors de l'induction de l'anesthésie dans un centre de chirurgie périatrique externe. Cent trente-quatre patients âgés de 2-10 ans, ASA I ou II) ont été divisés en deux groupes, le groupe traitement fut accompagné alors que pour le groupe "contrôle», aucun parent n'accompagnait l'enfant. Avant et aprés une semaine de la chirurgie, les craintes de l' enfant et son comportement furent évalués par les tests de "Hospital Fears Inventory" (HFI) et le «Behavioural Questionnaire» $(B Q)$ et l'anxiété des parents fut évaluée par le questionnaire des parents (PQ). Le test du "Global Mood Scale" (GMS) a été utilisé afin d'évaluer le comportement de l'enfant et le test du "Visual Analogue Scale » (VAS) fut utilisé afin d'évaluer l'anxiété des parents à l'arrivée de la chirurgie et a l' induction de l'anesthésie. Tous les patients et les parents étaient perturbés par l'expérience, mais au même degré entre le groupe "traitement " et le groupe " contrôle». Des sous-groupes de parents "calmes» et «anxieux ont été identifiés. Les enfants des sous-groupes "calmes-traitement" et "calmes-contrôle" et "anxieux-contrôle» étaient perturbés d' une façon similaire lors de l' induction. Les enfants du groupe "anxieux-traitement» étaient les plus perturbés lors de l'induction et significativement plus que le sous-groupe "anxieuxcontrole ". L'état d' anxiété préopératoire des parents était aussi relié aux craintes de l' enfant et à son comportement une semaine après la chirurgie. Ainsi, l' anxiété parentérale doit être évaluée dans la période préopératoire afin de calmer les parents présents à l'induction s'ils le désirent et les parents anxieux doivent être exclus et doivent recevoir support et conseil. 
Hospitalization can be an unpleasant experience which has marked effects on a young child. ${ }^{1-4}$ The benefits of treating paediatric surgical patients as outpatients to minimize the psychological stress of admission and parental separation were recognized as early as $1909 .^{5}$ Although influenced by improvements in anaesthesia and surgery, economic factors have also dictated changing patterns in patient care, with day surgery rapidly gaining popularity over the last decade. ${ }^{6-7}$. This has been accompanied by requests from parents to stay with their children for the induction of anaesthesia.

Some additional benefit might be expected from the presence of a parent at anaesthesia. ${ }^{8-9}$ Changes in the hospital environment in recent years make this more acceptable, but considerable modification to operating room procedures and facilities would be needed to allow large numbers of parents to accompany their children at induction. Convincing evidence that the benefits are sufficient is lacking. Therefore, this investigation was undertaken to determine the immediate and late effects on the child's mood and parents' anxiety following anaesthesia and surgery in which the parent was allowed to be present at induction of anaesthesia.

\section{Methods}

The study was approved by the Hospital Committee on Medical and Dental Evaluation, and informed parental consent was obtained preoperatively. One hundred and thirty-four paediatric surgical patients aged two to ten years, who were treated in the Day Surgery Centre of the Montreal Children's Hospital were studied. All children were otherwise healthy (ASA physical status I or II), with facility in English or French, and accompanied by a parent with whom they usually lived. The patients were divided into two groups, a "treatment" group, in which the parent was to be present at the induction of anaesthesia, and a "control" group, in which the parent was separated from the child at the door of the operating room suite in the usual manner.

Group assignment was by day of the week so that all children on a given day would be accompanied by a parent. There was a cross-over at the end of each week so that parents were present at induction on different days of the week in consecutive weeks to ensure that all types of surgical cases were represented in both groups. Although selection was not randomized, biases were avoided by rotation of days of the week, and contamination between groups (the presence of families from treated and control groups intermingling in the operating room area) was avoided by having all parents present at induction, or not, on any given day. Contamination would have been a considerable problem with random assignment.

All patients were treated in a routine manner with regard to preoperative examination, anaesthesia, surgery and postoperative care. The nature of the study was explained to the family at the preoperative visit. All were told that the purpose was to study their reactions to surgery, without identifying parental presence as the specific factor under investigation. However, the group assignment (treatment or control) was not given until they arrived for surgery. No parents refused to be present, but two who insisted were allowed to be present, but the data were excluded from the study. Standard measures were used to assess the responses of the child and parent at the preoperative assessment, the time of surgery and one week postoperatively.

\section{Measures used to assess child's behavioural responses}

HOSPITAL FEARS INVENTORY (HFI) ${ }^{10}$

The child's fears were rated by the HFI consisting of eight items which elicit fear in a normal population of children, such as visiting the dentist or doctor. The responses to each item were graded from "no fear" to "very much" (score 1-5). Standardization of responses was obtained by asking the child to select from pictures of five glasses, graded empty to full of water, to express the degree of fear that they felt. Observations were made at the preoperative assessment and the pictures were given to the parent to take home so that telephone replies could be obtained at one week postoperatively.

\section{GLOBAL MOOD SCALE (GMS)"}

The GMS is an observational scale which was used to assess the patient's mood at induction of anaesthesia. It is a seven-point scale which reflects the degree of disturbance from "playing happily" to "screaming" (score 1-7). Three operating room nurses were trained to make these observations on children before participating in the data collection for this study. They achieved interobserver agreement within one point in 95 per cent of observations. Forty per cent of the induction sequences studied were videotaped and the GMS was coded later by the trainer to ensure reliability in the scoring system. Agreement was greater than 90 per cent. All videotaping took place in the induction room and none in the operating room, with no systematic selection of children for entry into either of these areas. The mean GMS scores were similar for patients anaesthetized in both locations. Despite these attempts to obtain independent observations, the presence of a parent could not be concealed in the operating room or in the video-sequences, so some bias was inevitable.

BEHA VIOUR QUESTIONNAIRE (BQ) $)^{12}$

The assessment of behavioural changes as a result of the 
child's hospital experience was made by the BQ. This was administered first at the preoperative assessment clinic and then by telephone at one week postoperatively. This measure uses responses to a list of 28 questions compiled from intercorrelated observations of changes in psychological symptoms, such as enuresis, night terrors, or the need for a pacifier. Parents assessed the responses on a score of $1-5$, if the child "never demonstrated that behaviour" or if the "disturbance was present most of the time." Some questions were omitted or modified to ensure that the questionnaire was appropriate for the child's age. Changes in the responses before and after hospitalization were assumed to be the result of the hospital experience. The mean of the totals scored was used for further analysis.

\section{Measures used to assess parental anxiety}

PARENT'S QUESTIONNAIRE (PQ) ${ }^{13}$

This questionnaire consists of 16 questions about parental anxiety in relationship to the child's hospitalization as well as their previous general anxiety. It also concerns the way in which the parent has prepared the child for surgery. The mother assessed her anxieties about being a hospital patient herself, the way the child had reacted to medical procedures in the past, and how she expected her child to react to this experience. The complete questionnaire was used preoperatively at the time of the child's preoperative assessment and a shortened version (eliminating repetitive information), by telephone at one week postoperatively. The responses were rated as "no concerns" to "great anxiety" (scored 1-5). The mean of the total scores was then used for further analysis.

VISUAL ANALOGUE SCALE (VAS) ${ }^{14}$

The VAS is a $100 \mathrm{~mm}$ linear scale which was used to assess parental anxiety. The degree of anxiety felt by the parent was indicated by putting a cross over the line at the point which represented current anxiety. This was then scored according to whether the parent expressed "no fear" or "great anxiety" over the procedures (scale 0-100). Assessments were made on arrival at the Day Surgery Centre and immediately after induction of anaesthesia.

\section{Assessment of reliability of measures}

Reliability of the measures used was demonstrated by the intercorrelation between measures at different points in time. The child's reported fears (HFI) were significantly correlated at the preoperative visit and on the day of surgery in the reception area $(r=0.45, P<0.001)$. Similarly, the child's mood (GMS) and parent's anxiety (VAS) correlated with the move from the reception area

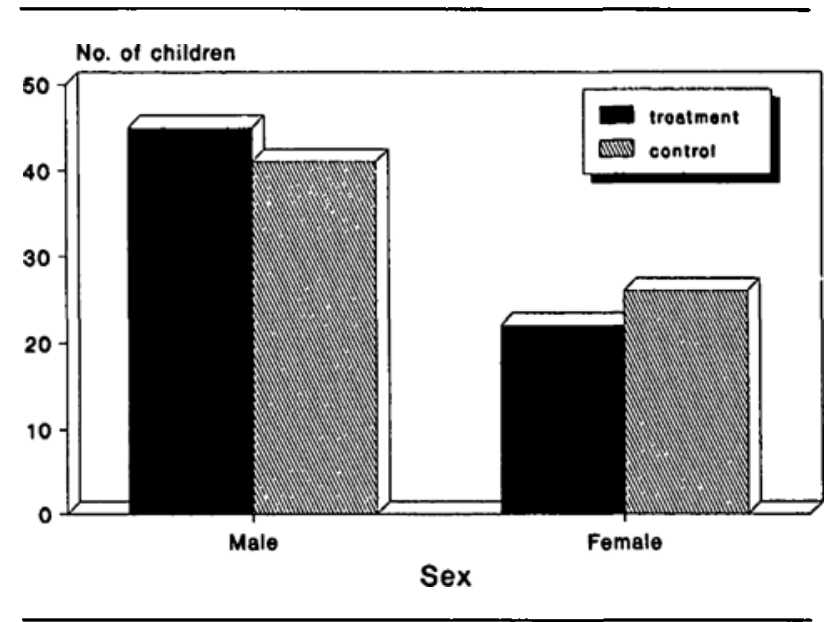

FIGURE I Distribution of boys and girls in "treatment" and "control" groups.

waiting room to induction of anaesthesia in the operating room $(r=0.34, P<0.001)$ or induction area $(r=0.59$, $P<0.001)$. Thus, these different approaches to the assessment of the family's anxiety appear to be measuring the same construct.

\section{Statistical analysis}

Data were initially tested for skewness and found to be normally distributed. Thus, parametric analysis was used. The changes within each patient and between groups were examined using a repeated measures ANOVA. All values are reported as mean $\pm \mathrm{SD}$. The score on the first time a measure was tested was used as the baseline for comparison with each subsequent value. For all analyses age was used as a covariate as it was expected to be a significant factor in the results. Multiple regressions were conducted to determine if preoperative variables predicted intra- or postoperative outcomes. All analyses were conducted via SPSS-PC v 3.0 .

\section{Results}

One hundred and thirty-four patients, aged $5.1 \pm 1.7$ (mean \pm SD) yr were studied. They included more boys than girls, with a male:female ratio of 1.73. There were 67 patients in the treatment and control groups, which were comparable in age $(4.9 \pm 1.5 \mathrm{yr}$ and $5.2 \pm 1.8 \mathrm{yr}$ respectively), sex (Figure 1), previous hospitalization (Figure 2), and type of surgery performed (Figure 3 ).

There were no significant differences between the treatment and control groups on any of the measures tested preoperatively (Table I). In the induction area the children became markedly upset (GMS: $P<0.0001$ ) and the parents were disturbed after induction (VAS: $P<$ 0.0001 ). One week after surgery, heightened parental anxiety (PQ: $P<0.0001)$ and increased behavioural upset 


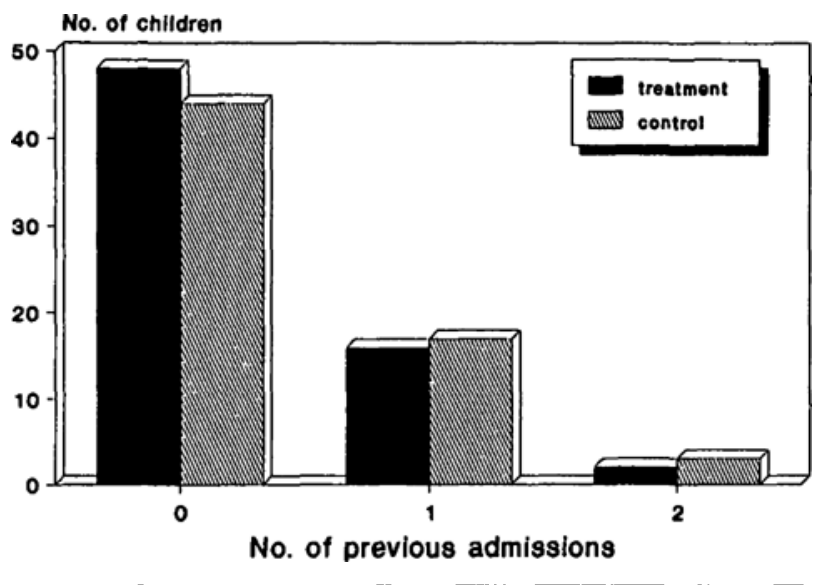

FIGURE 2 Previous hospitalization in "treatment" and "control" groups.

(BQ: $P<0.0001$ ) in the children, compared with the preoperative values, were demonstrated. These changes were the same in both groups (Table I).

Age was a significant covariate on most of the repeated measures ANOVA. Greater fear (HFI: $P<0.01$ ) and mood upset (GMS: $P=0.001$ ) were demonstrated in the younger patients on all analyses, but behavioural changes showed no significant correlation with age (BQ:P > 0.05 ). Further analyses for other factors using two-way ANOVA (group and other factor) with repeated measures yielded no significant differences for gender, language, type of surgery, time of day (morning or afternoon), place of induction (operating room or induction area), or previous hospitalization. The large number of anaesthetic personnel (19 staff anaesthetists, residents and anaesthetic technicians) involved in the study may have influenced the results, but the sample size was too small for analysis for this factor.

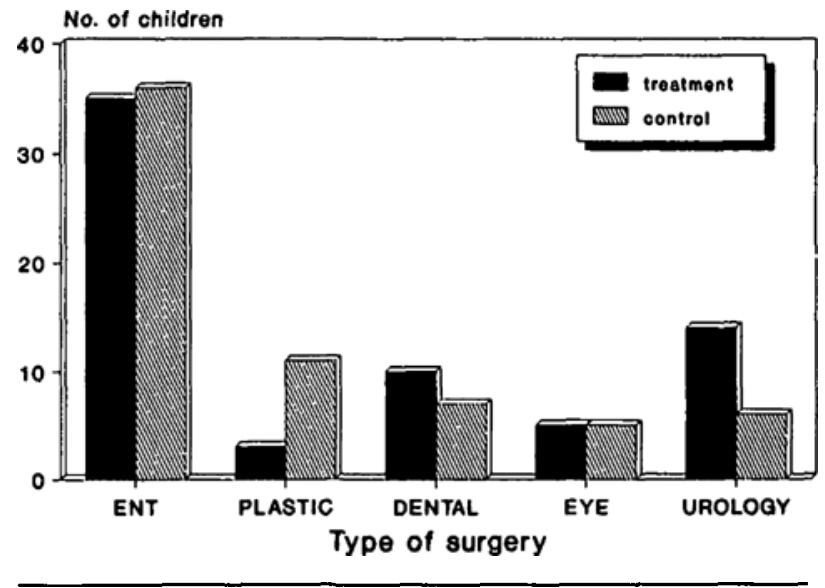

FIGURE 3 Types of surgery in "treatment" and "control" groups.

Some parents reported extreme discomfort after being present at induction of anaesthesia (to the point that one mother thought her child had died), suggesting that the anxiety levels of the parents may be a factor in outcome. The parents were then divided into subgroups of "anxious" or "calm" parents based on a median split of their anxiety scores in the reception area waiting room (median VAS $=42$ ). Forty-nine parents (36.6 per cent) were anxious (VAS $=77.2 \pm 16.7)$ and 63 parents $(47.0$ per cent) were calm (VAS $=15.9 \pm 12.6$ ). Children of "calm" parents did not differ in their mood as a result of having a parent accompany them at induction, behaving in the same way as children of "anxious" parents who were unaccompanied. Children of "anxious" parents were significantly more upset by having a parent present at induction than if they were separated (GMS: $P<0.05$ ). Parental anxiety levels were not appreciably altered by watching the induction, although a number of the "calm"

TABLE I Comparison of measured responses of children and parents in "treatment" and "control" groups.

\begin{tabular}{lllllll}
\hline Measure & Group & $n$ & $\begin{array}{l}\text { Preop } \\
l-3 w k\end{array}$ & $\begin{array}{l}\text { Reception } \\
\text { area }\end{array}$ & $\begin{array}{l}\text { Induction } \\
\text { area }\end{array}$ & $\begin{array}{l}\text { Postop } \\
\text { Iwk }\end{array}$ \\
\hline GMS (c) & T & 65 & & $1.7 \pm 1.1$ & $3.3 \pm 1.8$ & \\
& C & 65 & & $1.8 \pm 1.1$ & $3.3 \pm 1.7$ & \\
VAS (p) & T & 60 & & $42.8 \pm 32.2$ & $54.1 \pm 36.4$ & \\
& C & 65 & & $41.9 \pm 28.9$ & $52.3 \pm 33.1$ & \\
PQ (p) & T & 63 & $2.6 \pm 0.3$ & & & $3.0 \pm 0.5$ \\
& C & 58 & $2.5 \pm 0.3$ & & & $2.8 \pm 0.5$ \\
BQ (c) & T & 61 & $1.8 \pm 0.4$ & & & $3.1 \pm 0.2$ \\
& C & 64 & $1.8 \pm 0.4$ & & & $3.1 \pm 0.2$ \\
HFI (c) & T & 60 & $2.3 \pm 0.9$ & $2.2 \pm 0.7$ & & $2.2 \pm 0.8$ \\
& C & 56 & $2.3 \pm 0.7$ & $2.0 \pm 0.7$ & & $2.1 \pm 0.8$ \\
\hline
\end{tabular}

Values: means $\pm \mathrm{SD}$.

c: child, T: treatment, p: parent, C: control. 
TABLE II Relationship of child's mood (GMS) and parental anxiety (VAS) at induction of anacsthesia to parental anxiety (VAS) in the reception area preoperatively

\begin{tabular}{|c|c|c|c|c|c|}
\hline \multirow[b]{2}{*}{ Subgroup } & \multirow[b]{2}{*}{$n$} & \multicolumn{2}{|l|}{ Parental VAS } & \multicolumn{2}{|c|}{ Child's GMS } \\
\hline & & Reception & Induction & Reception & Induction \\
\hline Calm-treatment & 30 & $12.2 \pm 11.0$ & $31.2 \pm 33.5$ & $1.7 \pm 0.9$ & $3.4 \pm 1.6$ \\
\hline Calm-control & 33 & $19.2 \pm 13.3$ & $42.1 \pm 35.1$ & $2.1 \pm 1.4$ & $3.5 \pm 1.8$ \\
\hline Anxious-treatment & 24 & $78.8 \pm 16.6$ & $81.7 \pm 18.7$ & $1.7 \pm 1.2$ & $4.5 \pm 1.5$ \\
\hline Anxious-control & 25 & $72.5 \pm 18.0$ & $65.6 \pm 29.3$ & $1.6 \pm 0.8$ & $3.4 \pm 1.5$ \\
\hline
\end{tabular}

Values: mean $\pm \mathrm{SD}$.

parents felt less anxious after being present at their children's inductions, whilst some of the "anxious" parents found that separation helped to relieve their anxiety (Table II).

A correlation matrix of all measures was constructed. Variables were entered into a stepwise regression model with the child's GMS at induction, BQ and HFI scores at one week postoperatively, as the outcome measures. This showed that the child's preoperative $\mathrm{HFI}$ and $\mathrm{BQ}$, and the reception area GMS correlated with the GMS at induction. One week after surgery the child's BQ correlated with the parental VAS after induction; and the child's HFI with age, preoperative HFI and parental VAS in the reception area (Table III).

\section{Discussion}

Minimizing children's separation from their parents is an important component of day surgical care. However, the results of this study show that the presence of a parent during induction of anaesthesia is not always beneficial. The most upset group of children at induction of anaesthesia were those who were accompanied by extremely anxious parents; and the level of parental anxiety preoperatively was reflected in the children's behaviour and fears one week later. The presence of "calm" parents at induction made no difference to the children, but for some of these parents it was helpful in decreasing anxiety

TABLE III Stepwise regression of variables predicting the child's responses to anaesthesia and surgery

\begin{tabular}{llr}
\hline Outcome measure & Variable & Beta value \\
\hline GMS at induction (c) & HFI 1-3 wk preop (c) & $0.3844 \dagger$ \\
& BQ I-3 wk preop (c) & $0.3182 \dagger$ \\
& GMS in reception (c) & $0.2498^{*}$ \\
BQ 1 wk postop (c) & VAS post-induction (p) & $0.2910^{*}$ \\
HFI 1 wk postop (c) & HFI 1-3 wk preop (c) & $0.4678 \ddagger$ \\
& Age in yr (c) & $-0.2712^{*}$ \\
& VAS in rcception (p) & $0.2603^{*}$ \\
\hline
\end{tabular}

$P$ value $*<0.05, \dagger<0.01, \ddagger<0.001$.

c: child, p: parent afterwards. The highest levels of anxiety were demonstrated in those anxious parents who were present at induction.

In contrast to these findings, Schulman $e t$ al.$^{8}$ studied 32 children undergoing tonsillectomy as in-patients, and found that the presence of a parent calmed the child during anaesthetic induction. More recently, Hannallah et al. ${ }^{9}$ came to the same conclusion in a study of day-care patients in which parents could choose to be present at induction. In these earlier studies the responses were assessed by the investigators. Preliminary observations by Hickmott et al. ${ }^{15}$ suggested that a parent does not always influence a child's mood at induction.

The design of the present study included all parents, because preselection of patients and parents may have accounted for the apparent benefits found previously. In addition, personal bias was avoided by having independent observers trained in coding the responses. The number of anaesthetic personnel involved in the study may have produced a more varied approach to the children, as some are more successful in producing a calm induction. ${ }^{16}$ Although the presence of only one anaesthetist $^{8,9}$ could have eliminated this variable, it is not a realistic approach to routine management.

Studies of this nature are difficult to design. Anxiety and behavioural responses resulting from hospitalization have complex and multifactorial origins. Short hospital admissions of less than a week may produce little disturbance in healthy children, ${ }^{2}$ while the mother's presence sometimes has an adverse effect on the child's behaviour during hospital procedures. ${ }^{17}$ Younger children (one to five years old) show greater emotional reactions to preoperative hospitalization than older children. ${ }^{19,20}$ The measures selected for this study appeared to be the most reliable and appropriate for our purpose, although not commonly used in the perioperative period. However, they have been applied in behavioural studies in other hospital settings $s^{1,9,14}$ and, despite some limitations, ${ }^{20}$ have proved to be reliable and sensitive. ${ }^{17-19}$

The number of children treated as outpatients has increased in recent years, ${ }^{7}$ so a reappraisal of this aspect 
of anaesthetic management is timely. The presence of a parent during induction of anaesthesia is frequently requested and might alleviate emotional stress in some families. Therefore, it is important to organize day-care facilities so that parents can be present at induction without disruption to the operating room schedule. However, almost half of the parents in this study were extremely anxious and their presence at induction is contraindicated. If a simple assessment of parental anxiety levels is made part of routine preoperative evaluation, the "anxious" and "calm" parents could be identified. Appropriately concerned parents may then be allowed to accompany their children at induction if they wish, whilst highly anxious parents should be excluded and offered additional counselling and support.

\section{References}

1 Ferguson $B F$. Preparing young children for hospitalization: a comparison of two methods. Pediatrics 1979 ; 64: 656-64.

2 Quinton $D$, Rutter $M$. Early hospital admissions and later disturbances of behavior: an attempted replication of Douglas' findings. Dev Med Child Neurol 1976; 18: 447-59.

3 Meyers EF, Muravchick S. Anesthesia induction technics in pediatric patients. A controlled study of behavioral consequences. Anesth Analg 1977; 56: 538-42.

4 Melamed $B G$, Siegel $L J$. Reduction of anxiety in children facing hospitalization and surgery by use of filmed modelling. J Consult Clin Psychol 1975; 43: 511-21.

5 Nicoll JH. The surgery of infancy. Br Med J 1909; 2: 753-4.

6 Steward DJ. Anaesthesia for paediatric out-patients. Can Anaesth Soc J 1980; 27: 412-16.

7 Johnson $G G$. Day care surgery for infants and children. Can Anaesth Soc J 1983; 30: 553-7.

8 Schulman JL, Foley JM, Vernon DTA, Allan D. A study of the effect of the mother's presence during anesthesia induction. Pediatrics 1967; 39: 111-4.

9 Hannallah $R$, Rosales $J K$. Experience with parents' presence during anaesthesia induction in children. Can Anaesth Soc J 1983; 30: 286-9.

10 Scherer $M W$, Nakamura $C Y$. A fear survey schedule for children (FSS-FC): a factor analytic comparison with manifest anxicty (CMAS). Behav Res Ther 1968; 6: 173-82.

11 Torrance JT. Children's reactions to intramuscular injections: a comparative study of needle and jet injections. Thesis, Master of Nursing. Case Western Reserve University, Cleveland, Ohio. 1968.
12 Vernon DTA, Schulman JL, Foley JM. Changes in children's behavior after hospitalization: some dimensions of response and their correlates. Am J Dis Child 1966; 3 : 581-93.

13 Melamed BG, Meyer R, Gee $C$, Soule L. The influence of time and type of preparation of children's adjustment to hospitalization. J Pediatr Psychol 1976; 31-7.

14 Clark PRS, Spear FG. Reliability and sensitivity in self-assessment and well-being. Bull $\mathrm{Br}$ Psychol Soc 1964; 17-9.

15 Hanallah RS, Abramowitz MD, Tae HO, Ruttiman VE. Residents' attitudes toward parents' presence during anesthesia induction in children: does experience make a difference? Anesthesiology 1984; 60; 598-601.

16 Hickmott KC, Shaw EA, Goodyer I, Baker R. A study into the effects of maternal presence at induction of general anaesthesia in children (Abstract). Procecdings of Scientific Meeting, Assocation of Paediatric Anacsthetists (Great Britain and Ireland) 1986; 22.

17 Shaw EG, Rough DK. Effect of mother presence on children's reaction to aversive procedures. J Pediatr Psychol 1982; 7; 33-42.

18 Lee JS, Greene NM. Parental presence and emotional state of children prior to surgery. Clin Pediatr 1969; 8: 126-30.

19 Steward DJ. Experiences with an outpatient anesthesia service for children. Anesth Analg 1973; 52: 877-80.

20 Winer GA. A review and analysis of children's fearful behavior in dental settings. Child Dev 1982; 53 : 1111-33. 